\title{
Mücadele Sporcularında Duygusal Yeme, Bilinçli Farkındalık ve Psikolojik İyi Oluş
}

\author{
Emotional Eating, Mindfulness and Psychological Well-Being in Combat Athletes
}

\author{
Yusuf SOYLU
}

\begin{abstract}
ÖZ
$\mathrm{Bu}$ araştırmanın amacı, mücadele sporcularında duygusal yeme, bilinçli farkındalık ve psikolojik iyi oluş arasındaki ilişkinin incelenmesidir. Araştırmaya 590 mücadele sporcusu (erkek $=407$, kadın $=183$ ) katılmıştır. Araştırmada duygusal yeme ölçeği, sporcu bilinçli farkındalık ölçeği ve psikolojik iyi oluş ölçeği kullanılmıştır. Araştırmanın bulgularına göre, sporcuların millilik durumuna göre incelendiğinde, mili sporcuların duygusal yeme ve alt boyutlarında diğer sporculara göre daha fazla duygusal yeme düzeylerine sahip oldukları görülmüştür $(\mathrm{p}<0.05)$. Duygusal yeme, bilinçli farkındalık ve psikolojik iyi oluş arasında istatistiksel olarak anlamlı fark olduğu belirlenmiştir $(\mathrm{p}<0.05)$. Duygusal yeme arttıkça farkındalık ve yeniden odaklanma düzeylerinde düşüş olurken yargılamama alt boyutunda artış olmaktadır. Duygusal yeme eğilimi ve psikolojik iyi oluş arasında ise negatif yönde bir ilişki olduğu ve duygusal yeme artışı psikolojik iyi oluşu azaltmaktadır. Bilinçli farkındalık düzeyi yükseldikçe psikolojik iyi oluş düzeyi de yükselmektedir. Araştırmanın sonuçlarına göre, duygusal yeme mücadele sporcularında farkındalık düzeylerinde bozulmalara neden olurken aynı zamanda psikolojik iyi oluşu da olumsuz yönde etkilemektedir. Bu etkilerin mücadele sporcuları için müsabakalara hazırlanırken kilo düşme süreçlerinde zorlanmalara fiziksel ve psikolojik olarak performans düşüşleri yaşamalarına neden olabileceği düşünülebilir.
\end{abstract}

Anahtar Kelimeler: Duygusal yeme, Bilinçli farkındalık, Psikolojik iyi oluş, Mücadele sporları, Sağlık

\begin{abstract}
The aim of this study is to examine the relationship between emotional eating, mindfulness and psychological well-being in combat athletes. 590 combat athletes $($ male $=407$, female $=183$ ) participated in the study. In the study, emotional eating scale mindfulness inventory for sport and psychological well-being scale were used. As a result of this study, national athletes were assessed differences in emotional eating, mindfulness and psychological well-being. The results showed that national team athletes were higher levels of emotional eating than other athletes $(p<0.05)$. Relationship of emotional eating, mindfulness and psychological wellbeing was determinant pearson correlation analysis. There was a significantly differences between emotional eating, mindfulness and psychological wellbeing $(p<0.05)$. As emotional eating increases, awareness and refocus levels decrease, while the subdimension of non-judgmental increases. On the other hand, there is a negative difference between emotional eating tendency and psychological well-being, and an increase in emotional eating decreases psychological well-being. As the level of conscious awareness increases, the level of psychological well-being also increases. According to the results of the study, while emotional eating causes impairment in the level of awareness in combat athletes, it also negatively affects psychological well-being. It can be thought that these effects may cause difficulties in weight loss processes and physical and psychological performance decreases for combat athletes while preparing for competitions.
\end{abstract}

Keywords: Emotional eating, Mindfulness, Psychological well-being, Combat athletes, Health

\footnotetext{
Bu çalışmada ilgili Üniversitenin Etik Kurulu’ndan 33490967-044-33120-2021 numara ile etik izin alınmıştır.

${ }^{1}$ Dr. Öğr. Üyesi, Yusuf SOYLU, Spor Bilimleri, Tokat Gaziosmanpaşa Üniversitesi Spor Bilimleri Fakültesi, soylusyusuf@ gmail.com, ORCID: 0000-0003-0609-0601
}

İletişim / Corresponding Author:

Yusuf SOYLU

e-posta/e-mail: soylusyusuf@gmail.com

Geliș Tarihi / Received: 26.06.2021

Kabul Tarihi/Accepted: 02.09.2021 


\section{GíRiș}

Mücadele sporlarında yeme alışkanlıkları ve eğilimleri düzenli kilo kontrolü sürecinde önemli bir etken olabilmektedir. Sporcular, antrenörler ve beslenme uzmanları için sporcuların yeme bozuklukları ve beslenme programındaki düzensizlikler performans için ciddi bir endișe oluşturmaktadır. ${ }^{1}$ Enerji tüketiminin yüksek olduğu sporcular için yarışma periyodunda belirli bir oranda düşük veya fazla kilonun performans1 etkileyebileceği ve bu nedenle yeme bozukluklarının daha sı görülebileceği belirtilmiştir. ${ }^{1,2}$

Yeme isteği, bir yiyeceğe karşı insanı harekete geçiren fizyolojik bir gereksinimin yanında duygusal bir ihtiyaç ve yeme problemi olarak ifade edilmektedir., ${ }^{3,4}$ Duygusal yeme davranışı psikolojik süreçler içerisinde hissedilen çeşitli olumsuz duygulara karşı verilen bir cevap olduğu belirtilmiştir., ${ }^{5,6}$ Stres, kaygı ve depresyon tarafindan tetiklenen yeme isteği düşük psikolojik iyi oluş, yeme bozukluğu semptomları ve zayıf duygu düzenleme ile yakından ilișkilidir. ${ }^{7,8}$ Mücadele sporları, birkaç saniye ile birkaç dakika arasında değişen hareket aralıkları içerisinde yüksek kalp atım hızı ve enerji talepleri yüksek düzeyde psikolojik ihtiyaçlar doğurabilmektedir. ${ }^{9} \quad$ Süel (2020) düşük performansın veya sosyal bir bozukluğun sporcuları duygusal yemeye yöneltebileceğini belirtmiştir. Dahası duygu düzenleme becerisinin duygusal yeme isteğinden negatif etkilenerek sporcularda fiziksel uygunluğun düşmesi veya psikolojik sorunların artmasına sebep olacaktır. ${ }^{10,11} \mathrm{Bu}$ durum karşısında, alternatif bir başa çıkma stratejisinin geliştirilmesiyle birlikte performansı olumsuz yönde etkilemeyecek, performansin gelişmesi ve arttırılması açısından daha verimli bir başa çıkma tarzı oluşturulabilir. ${ }^{12}$ Sporcularda duygusal yemenin taleplerini arttıran, duygusal ve fiziksel belirleyiciler üzerinde oluşturulan farkındalığın yeme isteğini kontrol edebilmelerini düşünülmektedir. ${ }^{13}$ sağlayabileceği

Kişisel farkındalığı, başa çıkma becerisi ve duyguları yönetme becerisi düșük olan kişilerin duygusal yemeye daha çok eğilimlidirler. ${ }^{14}$ Yeme bozukluklarında kilit bir rol oynayan bilinçli farkındalığın, spor performans1 öncesi, siras1 ve sonrasinda duyguların algılanması, düzenlenmesi ve yönetilmesi için alternatif bir duygu düzenleme becerisi olarak kullanılabileceğini ifade edilmektedir. ${ }^{15-18}$

Farkındalik kavramının spor performansında önemli bir yeri olmasının en önemli sebeplerinden biri olarak, farkındalık temelli uygulamaların duygu düzenleme becerisini arttırarak aşırı yemek yeme isteğinin önüne geçilmesinde etkin bir rol oynadığ 1 ifade edilmektedir. ${ }^{19}$ Farkındalık ve duygusal yeme arasındaki ilişkiyi gösteren çalışmalarda, farkındalık egzersizlerinin yeme isteğini azaltarak, aşırı yemeyi engellediği ve vücut kütle indeksinde bir azalmaya neden olduğu görülmüştür. ${ }^{16,20-22}$ Mücadele sporcularında fiziksel, fizyolojik ve psikolojik ihtiyaçların artması ve yoğun müsabaka stresiyle birlikte ortaya çıkan negatif etkilerin duyguları yemeye yöneltebileceği düşünülebilir. Bilgimize göre literatürde mücadele sporcularının duygusal yeme, bilinçli farkındalık ve psikolojik iyi oluş arasındaki ilişkiyi inceleyen çalıșma bulunmamaktadır. $\mathrm{Bu}$ bilgiler 1şı̆̆ında mevcut araştırmanın amacı, mücadele sporcularında duygusal yeme, bilinçli farkındalık ve psikolojik iyi oluş arasındaki ilişkinin incelenmesidir.

\section{MATERYAL VE METOT}

Araștırma ilişkisel tarama modelinde gerçekleştirilmiş olup, birden fazla değişken arasında ilişki olup olmadığını belirlemek için kullanılan bir yöntem türüdür. Araştırmaya farklı branşlardan 590 mücadele sporcusu $($ yaş $=22.5$; erkek $=407$, kadın $=$ 
183; milli sporcu $=230$ ) gönüllü olarak katılmıştır.

\section{Araştırmanın Etik Yönü}

Araştırma Helsinki Bildirgesine uygun şekilde gerçekleştirilmiş ve Tokat Gaziosmanpaşa Üniversitesi Etik Kurulu (E33490967-044-33120-2021) tarafindan onaylanmıştır.

\section{Veri Toplama Aracı}

Araştırmanın ikinci bölümünde, sporcuların duygusal yeme düzeylerini belirlemek için Garaulet ve arkadaşları (2012) tarafından geliştirilen ve Arslantaş ve ark., (2020) Türkçe uyarlaması yapılan 10 soru ve üç alt boyuttan (yeme isteğini engelleyememe 5, yiyeceğin türü 3 ve suçluluk hissi 2) oluşan Duygusal Yeme Ölçeği (DYÖ) kullanılmıştır. Ölçek dört seçenek içeren (Asla-0, Bazen-1, Genellikle-2 ve Her zaman3) puanlama türünden oluşmaktadır. Ölçekten alınan en yüksek puanın duygusal yeme davranışının da yüksek olduğunu göstermektedir. Sporcu Bilinçli Farkındalık Ölçeği, Thienot ve arkadaşları (2014) geliștirilen ve Türkçe uyarlaması Tingaz (2020) tarafından yapılmıştır. 15 soru ve 3 alt boyuttan (Farkindalı, Yargllamama ve Yeniden Odaklanma) oluşa ölçek 6'l1 Likert tipindedir. Sporcularda psikolojik iyi oluşu tespit edebilmek için Diener vd. (26'nin geliştirdiği ve Türkçe çevirisi Telef (2013) tarafından yapılan Psikolojik İyi Oluş ölçeği sekiz maddeden oluşmaktadır. Bir bireyin ilişkiler, benlik saygısı, amaç ve iyimserlik dahil olmak üzere çeşitli alanlardaki başarı algısını ölçmektedir. Ölçekten alınan puanlar 1 ile 7 arasında değişmekte ve yüksek puan daha iyi psikolojik iyi oluş halini göstermektedir.

\section{Verilerin İstatistiksel Değerlendirilmesi}

Elde edilen verilerin analizi için SPSS 24 istatistik programı kullanılmıştır. Verilerin normal dağılımı için Skewness ve Kurtosis değerleri incelenmiş olup, verilerin normal dağılım uygun olduğu görülmüștür. Sporcuların millilik durumu değişkeni için bağımsız örneklem $t$ testi kullanılmıştır. Duygusal yeme, bilinçli farkındalık ve psikolojik iyi oluş arasındaki ilişkiyi incelemek için Pearson ilişki testi kullanılmıştır. Duygusal yemenin bilinçli farkındalık ve psikolojik iyi oluş üzerindeki etkisi regresyon analizi ile test edilmiştir.

Çalışmada güven aralığı $\mathrm{p}<0.05$ olarak belirlenmiştir. Cohen $\mathrm{d}$ etki büyüklüğü, benzer çalışmalarla ilgili daha sağlam bilgiler sunmak için hesaplanmıştır. Çalışmada güven aralığ $1 \mathrm{p}<0.05$ olarak belirlenmiştir. Cohen d etki büyüklüğü, benzer çalışmalarla ilgili daha sağlam bilgiler sunmak için hesaplanmıştır. Etki büyüklüğü istatistikleri için eşikler aşağıdaki gibidir: 0.2, önemsiz; 0.6, küçük; 1.2, orta; 2.0, büyük; ve.2.0, çok büyük.

\section{BULGULAR VE TARTIŞMA}

Araştırmanın bu bölümünde, mücadele sporcularının millilik değişkenine göre duygusal yeme, bilinçli farkındalık ve psikolojik iyi oluş farkı ve ilişki ve regresyon analizleri sonuçları incelenecektir.
Tablo 1'de cinsiyet değişkenine ait sonuçlar incelendiğinde, yeme isteğini engelleyeme, suçluluk hissi ve duygusal yeme toplam puan da istatistiksel olarak anlamlı fark olduğu görülmüştür $(\mathrm{p}<0.05)$. 
Tablo 1. Millilik Durumuna Ait Duygusal Yeme, Bilinçli Farkındalık ve Psikolojik İyi Oluş Sonuçları

\begin{tabular}{|c|c|c|c|c|c|c|}
\hline & \multicolumn{6}{|c|}{ Millilik Durumu } \\
\hline & $\begin{array}{l}\text { Evet } \\
(n=230)\end{array}$ & $\begin{array}{l}\text { Hayır } \\
(n=360)\end{array}$ & $\mathbf{t}$ & $\mathbf{p}$ & $\begin{array}{c}\text { Etki } \\
\text { Büyüklüğüu }\end{array}$ & $\begin{array}{c}\text { Etki } \\
\text { Derecesi }\end{array}$ \\
\hline & $\overline{\mathbf{X}} \pm \mathbf{S S}$ & $\overline{\mathbf{X}} \pm \mathbf{S S}$ & & & & \\
\hline $\begin{array}{l}\text { Yeme İsteğini } \\
\text { Engelleyememe }\end{array}$ & $2.01 \pm 0.57$ & $1.84 \pm 0.56$ & 3.633 & $0.000 *$ & .30 & Küçük \\
\hline Yiyeceğin Türü & $2.36 \pm 0.69$ & $2.27 \pm 0.70$ & 1.476 & 0.140 & & \\
\hline Suçluluk Hissi & $2.19 \pm 0.67$ & $1.99 \pm 0.70$ & 3.457 & $0.001 *$ & .29 & Küçük \\
\hline Duygusal Yeme & $2.12 \pm 0.52$ & $1.95 \pm 0.49$ & 3.795 & $0.000 *$ & .33 & küçük \\
\hline Farkındalık & $4.87 \pm 0.70$ & $4.94 \pm 0.70$ & -1.175 & 0.240 & & \\
\hline Yargılamama & $4.22 \pm 0.91$ & $4.15 \pm 0.95$ & .849 & 0.396 & & \\
\hline Yeniden Odaklanma & $4.72 \pm 0.83$ & $4.74 \pm 0.80$ & -.265 & 0.791 & & \\
\hline $\begin{array}{ll}\text { Sporcu } & \text { Bilinçli } \\
\text { Farkındalık } & \end{array}$ & $4.60 \pm 0.60$ & $4.61 \pm 0.61$ & -.140 & 0.889 & & \\
\hline Psikolojik İyi Oluş & $5.67 \pm 1.16$ & $5.74 \pm 0.96$ & -.771 & 0.441 & & \\
\hline
\end{tabular}

$\mathrm{p}<0.05$

Tablo 2. Duygusal Yeme, Bilinçli Farkındalık ve Psikolojik İyi Oluş İlişkisi

\begin{tabular}{|c|c|c|c|c|c|c|c|c|c|c|}
\hline & & 1 & 2 & 3 & 4 & 5 & 6 & 7 & 8 & 9 \\
\hline 1 & $\begin{array}{l}\text { Yeme İsteğini } \\
\text { Engelleyememe }\end{array}$ & 1 & $.525^{* *}$ & $.433 * *$ & $.936 * *$ & $-.129 * *$ & $.169 * *$ & $-.151 * *$ & -.031 & $-.184 * *$ \\
\hline 2 & Yiyeceğin Türü & & 1 & $.297 * *$ & $.708 * *$ & -.080 & .075 & $-.085^{*}$ & -.030 & $-.116^{* *}$ \\
\hline 3 & Suçluluk Hissi & & & 1 & $.651 * *$ & -.046 & $.206^{* *}$ & .010 & $.093 *$ & -.045 \\
\hline 4 & Duygusal Yeme & & & & 1 & $-.121 * *$ & $.190 * *$ & $-.122 * *$ & -.040 & $-.168 * *$ \\
\hline 5 & Farkındalık & & & & & 1 & $.229 * *$ & $.456 * *$ & $.714 * *$ & $.321 * *$ \\
\hline 6 & Yargllamama & & & & & & 1 & $.272 * *$ & $.728 * *$ & $.103 *$ \\
\hline 7 & $\begin{array}{l}\text { Yeniden } \\
\text { Odaklanma }\end{array}$ & & & & & & & 1 & $.768 * *$ & $.455 * *$ \\
\hline 8 & $\begin{array}{l}\text { Sporcu Bilinçli } \\
\text { Farkındalık }\end{array}$ & & & & & & & & 1 & $.383 * *$ \\
\hline 9 & $\begin{array}{l}\text { Psikolojik İyi } \\
\text { Oluş }\end{array}$ & & & & & & & & & 1 \\
\hline
\end{tabular}

$* \mathrm{p}<0.05, * * \mathrm{p}<0.01$

Duygusal yeme, bilinçli farkındalık ve psikolojik iyi oluş arasındaki ilişki sonuçları tablo 2 de verilmektedir. Duygusal yeme ve alt boyutları ile sporcu bilinçli farkındalık alt boyutları ve psikolojik iyi oluş arasında negatif yönde anlamlı ilişki olduğu görülmüştür $\quad(p<0.05)$. Sporcu bilinçli farkındalık ve alt boyutları ile psikolojik iyi oluş arasında pozitif yönde anlamlı bir ilişki olduğu tespit edilmiştir $(\mathrm{p}<0.05)$.
Buna göre, Milli takım düzeyindeki sporcuların duygusal yeme eğilimlerinin diğer sporculara göre daha fazla olduğu tespit edilmiştir.

Duygusal yemenin farkındalik, yargılamama ve psikolojik iyi oluş üzerindeki etkisinin anlamlı bir etkisinin olduğu ve bu etkinin varyansın \% 0.8 'ni oluşturduğu görülmüştür $(\mathrm{R} 2=0.84, \mathrm{p}<$ $0.05)$. 
Mevcut araştırmanın sonuçlarına göre, milli sporcuların duygusal yeme eğilimlerinin diğer sporculara göre daha fazla olduğu görülmüsşür. Duygusal yeme ve sporcu bilinçli farkındalık alt boyutları farkındalık, yargılamama, yeniden odaklanma ve psikolojik iyi oluş arasında ise negatif yönde çok zayıf bir ilişki olduğu belirlenmiştir. Farkındalık, yeniden odaklanma ve sporcu bilinçli farkındalık ölçeği ile psikolojik iyi oluş arasında ise pozitif yönde zayıf bir ilişki, yargılamama alt boyutu ile negatif yönde çok zayıf bir iliş̧ki olduğu tespit edilmiş̧ir. Araştırmada, duygusal yemenin farkindalık ve yargılamama ve psikolojik iyi oluş üzerinde anlamlı düzeyde etkisinin olduğu sporcuların bilinçli farkındalık düzeyleri düştükçe duygusal yeme halinin farkında olmadıkları ve psikolojik olarak olumsuz etkilendiği söylenebilir.

Yapılan araştırmalarda, farklı faktörlerden etkilenen fizyolojik ve psikolojik süreçlerle birlikte fiziksel performansin belirleyicilerinden biri olan dikkatli beslenme düzeni ve fiziksel performansla ortaya çıkan yoğun duygusal deneyimden dolayı elit sporcularda yeme isteğinin açlıktan değil aksine duygusal yemeden kaynaklandığ ifade edilmektedir. ${ }^{12,28}$ Sporcular, optimal performansı elde edebilmek için beslenme programlarında çok yer verilmeyen yağ ve şeker içerikli besinlerin tüketilmemesi fakat şekerli ve yağl yiyeceklerin kortizol seviyesini azaltarak stres seviyesinde düşüşe ve ruh halinde olumlu etki yarattığ 1 için sporcuların bu tarz yiyecekleri yeme isteğinin artmasına neden olmaktadır. ${ }^{29,30} \mathrm{Bu}$ nedenle milli takım seviyesindeki elit sporcuların daha fazla duygusal yeme eğiliminde olmaları yoğun stres ve bask1 altındayken, yarışma stresi veya performans düşüşünden kaynaklanan kaygının fiziksel ve fizyolojik taleplerin karşılanmasını zorlaştırmaktadır. $\mathrm{Bu}$ yüzden olumsuz ruh halinden kaynaklanan psikolojik ihtiyaçlara cevap verme ve zihinsel ve psikolojik olarak durumunu manipüle etme tercihini yeme davranışına yönelterek karşılayabileceği düşünülebilir.

Araştırmacılar olumsuz ruh halleri ile duygusal yeme arasındaki ilişkinin duygusal yemeye yönelten önemli bir belirleyici olarak görüldüğünü ifade etmektedirler. ${ }^{5}$ Yapılan çalışmalarda, duygusal yeme, olumsuz ruh haline karş̧ basit ve tatmin edici bir başa çıkma stratejisi gibi görünse de zamanla alışkanlık oluşturması, fiziksel ve psikolojik olarak zorlayıc1 bir durum ortaya çıkardığında duygu düzenleme becerisini de olumsuz etkileyerek farklı sorunlar ve kilo problemi oluşturabilir. ${ }^{12,31}$ Kişinin duygusal tepkilerine, algisal deneyimlerine ve bedensel duyumlarına dikkat etme yeteneği ister duygusal ister fiziksel olsun, kişinin deneyimine karşı bir açıklık ve kabul tutumu içeren farkındalı̆̆ın önemli bir yönüdür. ${ }^{32,33}$ Yeme davranışı ile ilgili olarak, araştırmalar, sürekli bilinçli farkındalık ve kilo alımı ile arasında olumsuz ilişkiler olduğunu bildirmiştir. ${ }^{34}$ Dahası, bilinçli farkındalı̆̆ı̆n duygusal ve kontrolsüz yemeyle ve ayrica duygusal yeme ile ilişkili yapılarla olumsuz ilişkili olduğu gösterilmiştir. ${ }^{35,36}$

İnsanın duygusal yemeden kaynaklı olarak ortaya çıka duyguları yönetme becerisinin düşük olması, başa çıkma becerisi ve kişisel farkındalığ 1 ile ilgilidir. $^{14}$ Yapılan araştırmalara göre duygusal yemeyi kontrol altında tutabilmenin en önemli yolunun hangi duyguların duygusal yemeyi tetiklediğinin farkında olmaktır. ${ }^{37,38}$ Duygusal yiyiciler, duygusal olmayan yiyicilerle karşılaştırıldığında, stresörlere tepki olarak yemek yeme, daha sık atıştırma ve daha fazla tatlı ve yüksek yağlı yiyecek tükettiğini bildirmektedir. ${ }^{39,40}$

Araştırmamızın sonuçlarına göre, sporcunun bilinçli farkındalık seviyesinin artmasiyla birlikte duygusal karmaşıklıklarından uzaklaşacağı ve ruh halinin farkında olarak olumsuz ruh hallerinden daha az etkilenebileceği söylenebilir. 
Tablo 3. Duygusal Yeme, Bilinçli Farkındalık ve Psikolojik İyi Oluş Regresyon Analizi Sonuçları

\begin{tabular}{|c|c|c|c|c|c|}
\hline & $\mathbf{R}^{2}$ & $\Delta \mathbf{R}^{2}$ & $\boldsymbol{\beta}$ & $\mathbf{t}$ & $\mathbf{F}$ \\
\hline Duygusal Yeme & .091 & .084 & .061 & 14.190 & 14.588 \\
\hline Farkındalık & & & $-.070 *$ & -2.165 & \\
\hline Yargılamama & & & $.136^{*}$ & 6.043 & \\
\hline Yeniden Odaklanma & & & -.057 & -1.869 & \\
\hline Psikolojik İyi Oluş & & & $-.059 *$ & -2.697 & \\
\hline
\end{tabular}

\section{SONUÇ VE ÖNERILLER}

$\mathrm{Bu}$ çalışmanın sonucuna göre, mücadele sporcularında duygusal yeme, sporcuların bilinçli farkındalık düzeylerinde etkili olduğu ve psikolojik iyi oluşa olumsuz etkilemektedir. Özellikle mücadele sporlarında düzensiz yeme ve fazla kilonun müsabakaya katılım ve performans açısından önemli bir rol oynadığı düşünüldüğünde, elit seviyedeki sporcular için bilinçli farkındalık düzeylerinin artışı duygusal yeme gibi bozuklukların etkisini azaltabileceği ve psikolojik olur iyi ve hazır oluşu tetikleyeceği söylenebilir. İleride yapılacak bilinçli farkındalık temelli uygulamaların sporcuların duygusal yeme eğilimlilerini, psikolojik ve zihinsel süreçlerine nasıl katkı sağlayarak alana 1 şı tutacağ düşünülmektedir.

KAYNAKLAR

1. Sundgot-Borgen, J. and Torstveit, M.K. (2004) "Prevalence of Eating Disorders in Elite Athletes is Higher Than in The General Population". Clinical Journal of Sport Medicine: Official Journal of the Canadian Academy of Sport Medicine, 14(1), 25-32. https://doi.org/10.1097/ 00042752-200401000-00005

2. Colak, A, Sahin, İ, Soylu, Y, Koc, M. and Ocal, T (2020). "Weight Loss Methods and Effects on The Different Combat Sports Athletes". Progress in Nutrition, 22 (1-S), 119-124. https://doi.org/10.23751/ pn.v22i1- S.9803

3. Greeno, C.G. and Wing, R.R. (1994). "Stress-induced Eating". Psychological Bulletin, 115 (3), 444-464. https://doi.org/10.1037/0033-2909.115.3.444

4. Lafay, L, Thomas, F, Mennen, L, Charles, M.A Eschwege, E, Borys, J.M, Basdevant, A. and Fleurbaix Laventie Ville Santé Study Group (2001). "Gender differences in the Relation Between Food Cravings and Mood in An Adult Community: Results From The Fleurbaix Laventie Ville Santé Study". The International Journal of Eating Disorders, 29(2), 195-204 https://doi.org/ 10.1002/1098108x(200103)29:2<195 ::aideat 1009>3.0.co;2-n

5. Suel, E. and Soylu, Y. (2020). "Emotional Eating Tendencies and General Health in Athletes: Gender Role". Ambient Science, 07 (Sp1), 170-175. https://doi. org/10.21276/ambi.2020.07.sp1.oa21

6. Garaulet, M, Canteras, M, Morales, E, López-Guimera G., Sánchez-Carracedo, D. and Corbalán-Tutau, M.D. (2012). "Validation of a Questionnaire on Emotional Eating for Use in Cases of Obesity: The Emotional Eater Questionnaire (EEQ)". Nutricion Hospitalaria, 27 (2), 645-651.https://doi.org/10.1590/S0212-1611201200020 0043
7. Braden, A, Musher-Eizenman, D, Watford, T. and Emley, E. (2018). "Eating When Depressed, Anxious, Bored, or Happy: Are Emotional Eating Types Associated With Unique Psychological and Physical Health Correlates?". Appetite, 125, 410-417. https://doi.org/10. 1016/j.appet.2018.02.022

8. Devonport, T.J, Nicholls, W. and Fullerton, C. (2019). "A Systematic Review of The Association Between Emotions and Eating Behaviour in Normal and Overweight Adult Populations". Journal of Health Psychology, 24 (1), 3-24. https://doi.org/10.1177/135 9105317697813

9. Vasconcelos, B.B, Protzen, G.V, Galliano, L.M, Kirk, C and Del Vecchio, F.B. (2020). "Effects of High-Intensity Interval Training in Combat Sports: A Systematic Review with Meta-Analysis. Journal of Strength and Conditioning Research", 34 (3), 888-900. https://doi.org/ 10.1519/JSC.0000000000003255

10. Suel, E. (2020). "The Relationship Between Emotional Eating and General Health Among Professional Basketball Players". Progress in Nutrition, 22 (2-S), e2020020. https://doi.org/10.23751/pn.v22i2-S.10575

11. Sahin, I. (2020). "The Relationship Between Emotional Eating and Mindfulness Among Wrestlers". Progress in Nutrition, 25(22), e2020010. https://doi.org/10.23751/ pn.v22i2-S.10513

12. Devonport, T.J. and Nicholls, Chen-Wilson J. (2021). 19 Emotional Eating. In: Ruiz \& Robazza (Ed.). Feelings in Sport: Theory, Research, and Practical Implications for Performance and Well-being. New York: Routledge. https://doi.org/10.4324/9781003052012 
13. Dalen, J, Brody, J.L, Staples, J.K. and Sedillo, D. (2015). "A Conceptual Framework for the Expansion of Behavioral Interventions for Youth Obesity: A FamilyBased Mindful Eating Approach”. Childhood Obesity, 11 (5), 577-584. https://doi.org/10.1089/chi.2014.0150

14. Young, DA. (2016). Emotional Eating, Stress, and Coping Styles in Early Adolescence (Doctoral Thesis) Graduate Faculty of Baylor University, US. Available from ProQuest Dissertations \& Theses Global. (1834505601).

15. Sala, M, Shankar Ram, S, Vanzhula, I.A. and Levinson, C.A. (2020). "Mindfulness and Eating Disorder Psychopathology: A Meta-Analysis". The Internationa Journal of Eating Disorders, 53 (6), 834-851. https://doi. org/10.1002/eat.23247

16. Buffington, B. C, Melnyk, B.M, Morales, S, Lords, A and Zupan, M.R. (2016). "Effects of an Energy Balance Educational İntervention and The COPE Cognitive Behavioral Therapy Intervention For Division I U.S. Air Force Academy Female Athletes". Journal of the American Association of Nurse Practitioners, 28 (4), 181-187. https://doi.org/10.1002/2327-6924.12359

17. Peña-Sarrionandia, A, Mikolajczak, M. and Gross, J.J. (2015). "Integrating Emotion Regulation and Emotiona Intelligence Traditions: A Meta-Analysis". Frontiers in Psychology, 6, 160. https://doi.org/10.3389/fpsyg.2015. 00160

18. Gross, J.J. (2014). Handbook of Emotion Regulation (2nd ed.). New York: Guilford Press.

19. Leahey, T.M, Crowther, J.H. and Irwin, S.R. (2008). "A Cognitive-Behavioral Mindfulness Group Therapy Intervention For The Treatment of Binge Eating in Bariatric Surgery Patients". Cognitive Behavioral Practice, 15 (4), 364-375.

20. Alberts, H.J, Mulkens, S, Smeets, M. and Thewissen, R. (2010). "Coping with Food Cravings. Investigating The Potential of A Mindfulness-Based İntervention", Appetite, 55 (1), 160-163. https://doi.org/10.1016/j. appet.2010. 05.044

21. Kristeller, J.L. and Hallett, C.B. (1999). "An Exploratory Study of a Meditation-based Intervention for Binge Eating Disorder". Journal of Health Psychology, 4 (3) 357-363. https://doi.org/10.1177/135910539900400305

22. Tapper, K, Shaw, C, Ilsley, J, Hill, A.J, Bond, F.W. and Moore, L. (2009). "Exploratory Randomised Controlled Trial of A Mindfulness-Based Weight Loss İntervention For Women”. Appetite, 52 (2), 396-404. https://doi.org/ 10.1016/j.appet.2008.11.012

23. Arslantaş, H, Dereboy, F, Yüksel, R. ve İnalkaç, $\mathrm{S}$. (2020). “Duygusal Yeme Ölçeği’nin Türkçe Çevirisinin Geçerlik ve Güvenirlik Calıșması”. Türk Psikiyatri Dergisi, 31 (2), 122-30.

24. Thienot, E, Jackson, B, Dimmock, J, Grove, J.R, Bernier, M. and Fournier, J.F. (2014). "Development and Preliminary Validation of The Mindfulness Inventory For Sport”. Psychology of Sport and Exercise, 15 (1) 72-80. https://doi.org/10.1016/j.psychsport.2013.10.003

25. Tingaz, E.O. (2020). "Sporcu Bilinçli Farkındalık (Mindfulness) Ölçeği: Türkçe' ye Uyarlama, Geçerlik ve Güvenirlik Çalışması”. SPORMETRE, 18(1), 71-80.
26. Diener, E, Wirtz, D, Tov, W, Kim-Prieto, C, Dong-won, C, Oishi, S. and et al. (2010). "New Well-being Measures: Short Scales to Assess Flourishing and Positive and Negative Feelings". Social Indicator Research, 97, 143-156. https://doi.org/10.1007/s11205009-9493-y

27. Telef, B.B. (2013). "Psikolojik İyi Oluş Ölçeği: Türkçeye Uyarlama, Geçerlik Ve Güvenirlik Çalışması". Hacettepe Üniversitesi Eğitim Fakültesi Dergisi, 28 (3), 374-384

28. Lane, A.M, Devonport, T.J, Stanley, D. and Beedie, C (2016). "The Effects of Brief Online Self-Help İntervention Strategies on Emotions and Satisfaction With Running Performance". Sensoria J Mind Brain Culture, 12, 30-39. https://doi.org/10.7790/sa.v12i2.441

29. Singh, M. (2014). "Mood, Food, and Obesity". Frontier in Psychology, 5, 925. https://doi.org/10.3389/fpsyg. 2014.00925

30. Konttinen, H, Männistö, S, Sarlio-Lähteenkorva, S, Silventoinen, K. and Haukkala, A. (2010). "Emotiona Eating, Depressive Symptoms and Self-Reported Food Consumption". A Population-Based Study. Appetite, 54 (3), 473-479. https://doi.org/10.1016/j.appet.2010.01.0 14

31. Elfhag, K. and Rössner, S. (2005). "Who Succeeds in Maintaining Weight Loss? A Conceptual Review of Factors Associated With Weight Loss Maintenance and Weight Regain". Obesity Reviews: An Official Journal of the International Association for the Study of Obesity, 6 (1), 67-85. https://doi.org/10.1111/j.1467-789X.2005. 00170. $\mathrm{x}$

32. Creswell, J.D. (2017). "Mindfulness Interventions". Annual Review of Psychology, 68, 491-516. https://doi.org/10.1146/annurev-psych-042716-051139

33. Quaglia, J.T, Braun, S.E, Freeman, S.P, McDaniel, M.A. and Brown, K.W. (2016). "Meta-Analytic Evidence for Effects of Mindfulness Training on Dimensions of SelfReported Dispositional Mindfulness". Psychological Assessment, 28 (7), 803-818. https://doi.org/10.1037/pas 0000268

34. Mantzios, M, Wilson, J.C, Linnell, M. and Morris, P. (2015). "The Role of Negative Cognition, Intolerance of Uncertainty, Mindfulness, and Self-Compassion in Weight Regulation among Male Army Recruits". Mindfulness, 6 (3), 545-552.

35. Katterman, S.N, Kleinman, B.M, Hood, M.M, Nackers, L.M. and Corsica, J.A. (2014). "Mindfulness Meditation As An İntervention for Binge Eating, Emotional Eating, and Weight Loss: A Systematic Review". Eating Behaviors, 15 (2), 197-204. https://doi.org/10.1016/j. eatbeh.2014.01.005

36. Lattimore, P. (2020). "Mindfulness-Based Emotional Eating Awareness Training: Taking The Emotional Out of Eating". Eating and Weight Disorders: EWD, 25 (3), 649-657. https://doi.org/10.1007/s40519-019-00667-y

37. Gianini, L.M, White, M.A. and Masheb, R.M. (2013) "Eating Pathology, Emotion Regulation, and Emotional Overeating in Obese Adults with Binge Eating Disorder". Eating Behaviors, 14 (3), 309-313. https://doi.org/10.1016/j.eatbeh.2013.05.008

38. Meyer, C, Leung, N, Barry, L. and De Feo, D. (2010). "Emotion and Eating Psychopathology: Links With Attitudes Toward Emotional Expression among Young Women". The International Journal of Eating Disorders, 43 (2), 187-189. https://doi.org/10.1002/eat.20659 
39. Camilleri, G.M, Méjean, C, Kesse-Guyot, E, Andreeva, V.A, Bellisle, F, Hercberg, S. and Péneau, S. (2014).

"The Associations between Emotional Eating and

Consumption of Energy-Dense Snack Foods Are Modified By Sex and Depressive Symptomatology". The Journal of Nutrition, 144 (8), 1264-1273. https://doi.org/10.3945/jn. 114.193177

40. O'Connor, D.B, Jones, F, Conner, M, McMillan, B. and Ferguson, E. (2008). "Effects of Daily Hassles and Eating Style on Eating Behavior". Health Psychology: Official Journal of the Division of Health Psychology, American Psychological Association, 27 (1S), S20-S31. https:// doi.org/10.1037/0278-6133.27.1.S20. 